\title{
Triple-negative and HER2-positive breast cancers found by mammography screening show excellent prognosis
}

\author{
Johanna Alanko ${ }^{1}$ D $\cdot$ Minna Tanner ${ }^{2} \cdot$ Ritva Vanninen $^{3} \cdot$ Anssi Auvinen $^{4} \cdot$ Jorma Isola $^{5}$
}

Received: 13 October 2020 / Accepted: 15 December 2020 / Published online: 8 January 2021

(c) The Author(s) 2021

\begin{abstract}
Purpose Our purpose was to explore the prognosis of aggressive breast cancers of the HER2 oncogene amplification $(\mathrm{HER} 2+)$ and triple-negative $(\mathrm{TN})$ subtypes detected by screening, as well as the prognosis of interval cancers (clinically due to symptoms between screening rounds) and cancers in screening nonparticipants.

Methods The study population comprised of 823 breast cancers in women aged 50-69 years from 2006-2014. Of these, 572 were found by screening mammography (69\%), 170 were diagnosed between the screening rounds (21\%), and 81 were diagnosed in women who did not participate in the screening program $(10 \%)$.

Results The majority of all HER $2+(59 \%)$ and TN cancers $(57 \%)$ in this age group were detected by screening. Screendetected HER2 + tumors were small (median $12 \mathrm{~mm}$ ), and node-negative (84\%). During a median follow-up of eight years, the distant disease-free survival of screen-detected HER $2+$ and TN cancers was better than that of interval and nonparticipant cancers (age-adjusted $\mathrm{HR}=0.16,95 \% \mathrm{CI} 0.03-0.81$ and $\mathrm{HR}=0.09,95 \% \mathrm{CI} 0.01-0.79$, respectively). In nonparticipants, the distant disease-free survival of these cancers was worse than in participants (age-adjusted HR $=2.52,95 \%$ CI $0.63-10.11$ and $\mathrm{HR}=5.30,95 \% 1.16-24.29$, respectively).

Conclusion In the 50-69 age group, the majority of HER $2+$ and TN cancers can be found by a quality assured populationbased mammography screening. Despite their generally aggressive behavior, after a median follow-up of 8 years, distant disease-free survival was over $90 \%$ of these cancers detected by screening. The worst prognosis of these cancers was in women who did not participate in screening.
\end{abstract}

Keywords Mammography screening $\cdot$ HER2 positive $\cdot$ Triple-negative breast cancer $\cdot$ Prognosis

Johanna Alanko

johanna.alanko@fimnet.fi

1 Laboratory of Cancer Biology, Faculty of Medicine and Health Technology, Screening Clinic of Terveystalo, Tampere University, Tampere, Finland

2 Department of Oncology, Faculty of Medicine and Health Technology, Tampere University and Tays Cancer Centre, Tampere, Finland

3 Department of Clinical Radiology, School of Medicine, University of Eastern Finland, Kuopio University Hospital, Kuopio, Finland

4 Faculty of Social Sciences (Health Sciences), Tampere University, Tampere, Finland

5 Laboratory of Cancer Biology, Faculty of Medicine and Health Technology, Jilab Inc., Tampere University, Tampere, Finland

$\begin{array}{ll}\text { Abbreviations } \\ \text { HER2 }+ & \text { HER2 oncogene positive } \\ \text { TN } & \text { Triple-negative } \\ \text { ER } & \text { Estrogen receptor } \\ \text { PR } & \text { Progesterone receptor } \\ \text { HOR } & \text { Estrogen and progesterone receptor } \\ \text { SDBC } & \text { Screen-detected breast cancer } \\ \text { IBC } & \text { Interval breast cancer } \\ \text { PSBC } & \text { Participation in screening breast cancer } \\ \text { NSBC } & \text { No participation in screening breast cancer }\end{array}$

\section{Background}

Breast cancer screening aims to reduce mortality by allowing diagnosis before disease dissemination. Due to earlier diagnosis, screen-detected breast cancers (SDBCs) are smaller and less commonly spread to the axillary lymph nodes, which is partly an advantage gained by screening 
and lead time [1-3]. Biologically, SDBCs are often welldifferentiated, hormone receptor-positive, HER2 negative, and associated with low tumor proliferation activity (low Ki-67 expression) [1-5]. Because of the slower growth rate, these cancers are more likely detected by screening than rapidly growing cancers, which is called length bias [6].

Within the biological spectrum of breast cancers, those displaying gene amplification of human epidermal growth factor receptor $2(\mathrm{HER} 2+)$ and those that are triple-negative (TN, i.e., negative for ER, PR and HER2) are generally considered biologically aggressive tumor subtypes. For HER 2 + breast cancer, the prognosis has improved due to the introduction of targeted therapies [7-9]. For TN breast cancer, no targeted oncological treatments are currently available. TN patients are treated with surgery, radiation, and chemotherapy [10].

Several studies have reported a lower proportion of HER 2 + cancers in screen-detected than in clinically detected patients (age group 50 to 70 years). The proportion of HER 2 + breast cancer in screen-detected tumors has varied between 8 and $18 \%$, whereas in interval cancers, it has ranged from 13-44\% [2, 3, 11-13]. In women who had not participated in screening, the proportion of HER $2+$ breast cancers ranged from $13 \%-28 \%$ in three studies $[3,13,14]$. A recent study from Ireland showed that in women aged 50-66 years, HER $2+$ cancers constituted $13 \%$ of those found in screening, $19 \%$ in interval cancers, and $18 \%$ in patients who had not participated in screening [15]. Similar patterns have also been found for TN cancers. Only 4-7\% of screendetected cancers are of the TN type, while 9-16\% of interval cancers are of the TN type $[2,11,12,15]$. Few earlier studies have compared clinical and biological features within the HER2 + and TN subtypes according to the method of detection. Dawson et al. reported slightly better overall survival among screen-detected HER $2+$ and TN cancer patients compared to interval cancer patients, but the differences were not statistically significant [2].

We aimed to explore the prognosis of HER $2+$ or TN breast cancers found by screening and by symptoms between two screening rounds and in women of screening age (50-69 years) who did not participate in screening.

\section{Materials and methods}

\section{Setting}

The target population for the mammography screening program was women aged 50-60 years in 2006-2007, women aged 50-64 in 2008-2009, women aged 50-66 in 2010-2011, and women aged 50-68 years since 2012 . Women were invited for mammography screening every 2 years. Mediolateral, oblique, and craniocaudal views were available for both breasts. All mammograms were independently read by two radiologists. Switching from film mammography to full-field digital mammography (Senographe Essential and Senographe DS, GE Healthcare) took place in autumn 2007, and one more full-field digital mammography device was obtained in 2014 (MicroDose Mammography, Philips). The screening program complies with the European Guidelines for Quality Assurance in Mammographic Screening [16]. All women invited for screening were residents of the city of Tampere. During the study period, 12,131 women on average were invited yearly to the screening, and the participation proportion was $81.8 \%$ in the first screening round and $84.1 \%$ in subsequent rounds.

After double reading, suspicious and/or unclear mammograms were reviewed together, and a recall for additional examinations was decided by consensus. The recall rate was $2.9 \%$. If the finding could not be proven benign, a biopsy was taken by core needle or vacuum-assisted needle biopsy together with a fine needle or core needle biopsy of suspicious nodes. The detection rate of malignant findings was $0.78 \%$. Preoperative MRI was used in a minority of cases upon consideration of a multidisciplinary meeting.

Invasive breast cancers were treated by breast-conserving surgery or mastectomy. Sentinel lymph node biopsy was performed during surgery in $75 \%$ of screen-detected cancers. The frequency of sentinel node biopsies in operations of other cancers is not available. An axillary evacuation was performed for patients with sentinel node metastasis or preoperative evidence of axillary metastases. Postoperatively, the women received radiation therapy, adjuvant chemotherapy, and hormonal therapy according to the national guidelines. Trastuzumab has been included as part of adjuvant chemotherapy since 2006 for patients with HER2 + breast cancer. Neoadjuvant chemotherapy was given if the cancer was considered inoperable at the time of diagnosis.

\section{Study population}

We included all women in the target population of the mammography screening program diagnosed with invasive breast cancer for the first time. Women with in situ cancers were excluded. Additionally, women with previous in situ or invasive breast cancer diagnoses in the same or contralateral breast were excluded.

A total of 823 breast cancers in 805 patients matching these criteria were identified from the local pathology database. Of these cancers, 572 (from 559 patients) were detected by screening (SDBC). The median age of patients with screen-detected cancer was 60 . The number of cancers detected within two years after a normal mammography screening was 170 (interval breast cancers, IBCs) in 168 patients, with a median age of 59. Altogether 742 cancers were detected in 727 women who did participate in screening 
(participation in screening breast cancers $=$ PSBCs), while in women who did not participate in the screening program at all or skipped at least the previous screening mammography (nonparticipants), 60 patients had 63 breast cancers. For 18 women $(2.2 \%)$ with invasive cancer, no information about screening could be found. These cases were included in the nonparticipants (no participation in screening breast cancers $=$ NSBCs) group. The median age for these women was 59.

\section{Data}

The clinical, histopathological, biomarker, and follow-up data were collected retrospectively from the medical records and mammography screening database. Neoadjuvant chemotherapy was given in 10 SDBC, 8 IBC, and 23 NSBC cases, and in those cases, tumor size refers to the largest tumor diameter measured in mammography or ultrasound. Patients with metastases detected within two months from diagnosis were regarded as metastatic at entry and were therefore not included in the analysis of distant disease-free survival. All HER2 oncogene diagnoses were based on chromogenic in situ hybridization and analyzed in a single laboratory.

\section{Statistical analyses}

Frequency tables were analyzed by two-tailed Fisher's exact test. The date of the last follow-up for relapse-free or living patients was 2-12-2019. The median follow-up was 8 years when the time to distant metastasis, death, or loss from follow-up was recorded as end-points. Distant-metastasis-free survival time was estimated using the Kaplan-Meier method log-rank test used for comparisons between the groups. A Cox proportional hazards model was used for multivariable analyses in Stata. Analyses comparing biologic subgroups by the method of detection were performed by adding an interaction term to a model with the main effects and assessing the improvement in fit with a likelihood ratio test. The proportionality assumption was evaluated based on Schoenfeld residuals. Analyses were truncated at eight years, as proportionality was not confirmed in the entire follow-up. The results were, however, qualitatively similar for both full and truncated follow-up.

\section{Results}

\section{General histopathological features}

The majority of SDBCs were smaller than $2 \mathrm{~cm}$ pT1 (82\%) and node-negative pN0 (69\%), while the proportions were smaller for IBCs and NSBCs (pT1 53\%, pN0 52\% and pT1 $43 \%$, pN0 46\%, respectively, $p<0.0001$ for both comparisons to SDBCs). Biologically, IBC and NSBC were more aggressive than SDBC. Histological grade 3 was found only in $15 \%$ of SDBC, but in $35 \%$ of IBC, in $31 \%$ of NSBC (both $p<0.0001$ ), which demonstrates dedifferentiation during tumor growth. A high tumor proliferation rate $(\mathrm{Ki}-67 \geq 15 \%)$ was found in $35 \%$ of $\mathrm{SDBC}$, while $48 \%$ of IBC and $51 \%$ of NSBC (both $p<0.01$ ). The proportion of HER2-positive tumors was $10 \%$ in SDBC, $15 \%$ in IBC and $16 \%$ in NSBC $(p=0.051, p=0.07$, respectively). In SDBC the proportion of TN cases were $5 \%$, in IBC $6 \%$, and in NSBC $11 \%(p=0.31, p=0.03$, respectively) (Table 1).

In the study population of 806 patients with 824 breast cancers, 96 (12\%) cancers were HER2 + and 47 (6\%) were TN. Even though their proportion in HER2 + cases was lower in SDBC than in the other groups, more than half of the HER 2 + breast cancers, as well as the TN breast cancers were found by screening (59\% and 57\%, respectively). A quarter of the cases in the more aggressive subgroups were interval cancers (27\% and $23 \%$, respectively). Digital screening (31 of 37) mammography views of interval HER2 + and TN patients were reanalyzed. Only five cases had minimal changes in the place where cancer later appeared. Thus, almost all of them were true biological intervals and not false-negative interpretations of screening mammograms.

\section{Biological and clinical features of HER2 + and TN cancers}

Of the HER2 + and TN breast cancers detected by screening, the majority were smaller than $2 \mathrm{~cm}(79 \%$ and $81 \%$, respectively) and were node-negative (pN0 84\% and 70\%, respectively). In contrast, of the HER $2+$ interval cancers diagnosed between the two screening rounds, $58 \%$ were $2 \mathrm{~cm}$ or larger, and $62 \%$ had metastases in the axilla, while HER2 + breast cancers detected in screening nonparticipants were mostly larger than $2 \mathrm{~cm}$ (77\%), node-positive $(92 \%)$ and $62 \%$ of them had distant metastasis already at the time of diagnosis (Table 2). The majority of interval TN breast cancers were smaller than $2 \mathrm{~cm}(73 \%)$, but almost all TN breast cancers (89\%) that were diagnosed in women who did not participate in screening were $2 \mathrm{~cm}$ or larger (Table 3). The median tumor size was $13 \mathrm{~mm}$ for all luminal types, $16.5 \mathrm{~mm}$ for HER2 +, and $14.5 \mathrm{~mm}$ for TN tumors. The Ki-67 index medians were 10, 33, and 46 , respectively. Regardless of the method of detection, HER $2+$ and TN carcinomas were predominantly of histological grade 3 (in screening HER $2+53 \%$ and TN $70 \%$, interval $77 \%$ and $100 \%$, no participation $62 \%$ and $78 \%$ ) and displayed a high proliferation rate (Ki-67) (Tables 2, $3)$. 
Table 1 Histopathological features of invasive breast cancers according to the method of detection

\begin{tabular}{|c|c|c|c|c|}
\hline & $\begin{array}{l}\text { Screen-detected } \\
\text { cancers (SDBC) }\end{array}$ & Interval cancers (IBC) & $\begin{array}{l}\text { No participation in screen- } \\
\text { ing cancers (NSBC) }\end{array}$ & $p$-value \\
\hline Number of tumors & 572 & 170 & 81 & \\
\hline \multicolumn{5}{|l|}{ Tumor size } \\
\hline Smaller than $2 \mathrm{~cm}$ & $469(82 \%)$ & $90(53 \%)$ & $35(43 \%)$ & $\begin{array}{l}<0.0001(\text { SDBC versus IBC) } \\
<0.0001(\text { SDBC versus NSBC), } \\
<0,0001 \text { (PSBC versus NSBC) }\end{array}$ \\
\hline $2 \mathrm{~cm}$ or larger & $101(18 \%)$ & $78(46 \%)$ & $45(56 \%)$ & \\
\hline Tumor size unknown & $2(<1 \%)$ & $2(1 \%)$ & $1(1 \%)$ & \\
\hline \multicolumn{5}{|l|}{ Nodal status } \\
\hline pNO & $396(69 \%)$ & $88(52 \%)$ & $37(46 \%)$ & $<0.0001,<0.0001,<0,001$ \\
\hline $\mathrm{pN}+$ & $176(31 \%)$ & $82(48 \%)$ & $44(54 \%)$ & \\
\hline \multicolumn{5}{|l|}{ Distant metastasis } \\
\hline M0 & $568(99 \%)$ & $165(97 \%)$ & $63(78 \%)$ & $0.0335,<0.0001,<0.0001$ \\
\hline$M+$ & $4(1 \%)$ & $5(3 \%)$ & $18(22 \%)$ & \\
\hline \multicolumn{5}{|l|}{ Histological grade } \\
\hline Grade 1 & $211(37 \%)$ & $27(16 \%)$ & $17(21 \%)$ & \\
\hline Grade 2 & $265(46 \%)$ & $76(45 \%)$ & $27(33 \%)$ & \\
\hline Grade 3 & $88(15 \%)$ & $59(35 \%)$ & $25(31 \%)$ & $<0.0001,<0.0001,0.0034^{*}$ \\
\hline Grade unknown & $11(2 \%)$ & $8(5 \%)$ & $12(15 \%)$ & \\
\hline Ki- $67<15 \%$ & $367(64 \%)$ & $89(52 \%)$ & $40(49 \%)$ & $0.0052,0.0099,0.0413$ \\
\hline $\mathrm{Ki}-67 \geq 15 \%$ & $202(35 \%)$ & $81(48 \%)$ & $41(51 \%)$ & \\
\hline Ki-67 unknown & $3(<1 \%)$ & 0 & 0 & \\
\hline $\begin{array}{l}\text { Luminal type } \\
(\text { ER + and/or PR +, HER2-) }\end{array}$ & $485(85 \%)$ & $133(78 \%)$ & $59(73 \%)$ & \\
\hline HER 2 + & $57(10 \%)$ & $26(15 \%)$ & $13(16 \%)$ & $0.0509,0.0737,0.1339 * *$ \\
\hline Triple negative & $27(5 \%)$ & $11(6 \%)$ & $9(11 \%)$ & $0.3120,0.0267,0.0328 * * *$ \\
\hline Unknown receptor status & $3(<1 \%)$ & 0 & 0 & \\
\hline
\end{tabular}

Fisher's exact test was used for $p$-value calculation

$p$-values for the SDBC versus IBC, SDBC versus NSBC, and PSBC (SDBC + IBC) versus NSBC groups

$p N O$, no postoperative axillary metastases; $M O$, no distant metastases; $p N+$ axillar and $M+$ distant metastases; $K i-67$, tumor proliferation rate; $E R$, estrogen receptor; $P R$, progesterone receptor; HER2, HER2 oncogene amplification; triple-negative, negative for ER, PR, and HER2 ${ }^{*} p$-value refers to Grade 3 vs. Grade $1+$ Grade $2,{ }^{* *} p$-value refers to HER $2+$ vs Luminal type, ***p-value refers to TN vs Luminal type

\section{Prognosis}

Only $1 \%$ of SDBCs, $3 \%$ of IBC, and $22 \%$ of NSBC had distant metastases $(\mathrm{M}+)$ at the time of diagnosis (Table1). HER 2 + breast cancers found in women who had participated in screening (SDBC and IBC) were all distant metastasis-free at the time of diagnosis (Table 2). During the 8-year median follow-up, distant metastasis appeared in $44(6 \%)$ of all patients who did not have distant metastasis (M0) at the time of diagnosis. In SDBC, distant metastases appeared in only $5 \%$ of HER $2+$ cancer patients, $4 \%$ of $\mathrm{TN}$ cancer patients, and $1 \%$ of patients with luminal tumor type, while in IBC, the corresponding figures were 15 , 40 , and 12 and NSBC 40,29, and 12. The distant diseasefree survival of screen-detected HER $2+$ and TN cancers was better than that of interval and nonparticipant cancers (age-adjusted HR $=0.16,95 \%$ CI $0.03-0.81$ and $\mathrm{HR}=0.09$,
95\% CI 0.01-0.79, respectively). It should also be noticed that the distant disease-free survival of nonparticipant HER $2+$ and TN cancers was worse than that of PSBCs (age-adjusted $\mathrm{HR}=2.52,95 \% \mathrm{CI} 0.63-10.11$ and $\mathrm{HR}=5.30$, 95\% 1.16-24.29, respectively). Distant disease-free survival by the method of detection among HER2 + (Fig. 1), TN (Fig. 2), and luminal type (Fig. 3) cases is illustrated in Kaplan-Meier plots. SDBC had the most favorable prognosis in all three cancer subgroups, with no major differences by the method of detection across the tumor types (interaction $p=0.79$ in Cox analysis truncated at eight years, median follow-up then 92 months). Of the screen-detected cases, the patients with luminal-type cancer tended to experience superior distant metastasis-free survival. There were also indications for prognosis being worst for patients with TN SDBC (HR $=3.78,95 \%$ CI 0.44-32.37, compared to luminal-type SDBC), though the difference from HER2 + cancer 
Table 2 Histopathological features of HER2 + breast cancers in the detection groups

\begin{tabular}{|c|c|c|c|c|}
\hline & $\begin{array}{l}\text { Screen-detected } \\
\text { cancers (SDBC) }\end{array}$ & Interval cancers (IBC) & $\begin{array}{l}\text { No participation in screen- } \\
\text { ing cancers (NSBC) }\end{array}$ & $p$-value \\
\hline Number of tumors & 57 & 26 & 13 & \\
\hline \multicolumn{5}{|l|}{ Tumor size } \\
\hline Smaller than $2 \mathrm{~cm}$ & $45(79 \%)$ & $11(42 \%)$ & $2(15 \%)$ & $\begin{array}{l}0.002 \text { (SDBC versus IBC), } \\
<0.0001 \text { (SDBC versus NSBC), } \\
0.0011 \text { (PSBC versus NSBC) }\end{array}$ \\
\hline $2 \mathrm{~cm}$ or larger & $12(21 \%)$ & $15(58 \%)$ & $10(77 \%)$ & \\
\hline Size unknown & 0 & 0 & $1(8 \%)$ & \\
\hline \multicolumn{5}{|l|}{ Nodal status } \\
\hline pNO & $48(84 \%)$ & $10(38 \%)$ & $1(8 \%)$ & $<0.0001,<0.0001,<0.0001$ \\
\hline $\mathrm{pN}+$ & $9(16 \%)$ & $16(62 \%)$ & $12(92 \%)$ & \\
\hline \multicolumn{5}{|l|}{ Distant metastasis } \\
\hline M0 & $57(100 \%)$ & $26(100 \%)$ & $5(38 \%)$ & $1.00,<0.0001,<0.0001$ \\
\hline $\mathrm{M}+$ & 0 & 0 & $8(62 \%)$ & \\
\hline \multicolumn{5}{|l|}{ Histological grade } \\
\hline Grade 1 & $2(4 \%)$ & 0 & 0 & \\
\hline Grade 2 & $19(33 \%)$ & $6(23 \%)$ & $1(8 \%)$ & \\
\hline Grade 3 & $30(53 \%)$ & $20(77 \%)$ & $8(62 \%)$ & $0.1364,0.1353,0.2605 *$ \\
\hline Grade unknown & $5(9 \%)$ & 0 & $4(31 \%)$ & \\
\hline $\mathrm{ER}+$ and/or PR + & $34(60 \%)$ & $10(38 \%)$ & $8(62 \%)$ & $0.0978,1.000,0.7760$ \\
\hline ER-,PR- & $23(40 \%)$ & $16(62 \%)$ & $5(38 \%)$ & \\
\hline $\mathrm{Ki}-67<15 \%$ & $7(12 \%)$ & $6(23 \%)$ & 0 & $0.3508,0.3361,0.2031$ \\
\hline Ki- $67 \geq 15 \%$ & $49(86 \%)$ & $20(77 \%)$ & $13(100 \%)$ & \\
\hline Ki-67 unknown & $1(2 \%)$ & 0 & 0 & \\
\hline
\end{tabular}

Fisher's exact test was used for $p$-value calculation

$p$-values compare SDBC versus IBC and SDBC versus NSBC and PSBC (SDBC + IBC) versus NSBC groups

$p N O$, no postoperative axillary metastases; $M O$, no distant metastases; $p N+$, axillar and $M+$, distant metastases; Ki-67, tumor proliferation rate; $E R$, estrogen receptor; $P R$, progesterone receptor; $H E R 2$, HER2 oncogene amplification

* $p$-value compares Grade 3/(Grade $1+$ Grade 2)

was not significant $(\mathrm{HR}=3.27,95 \%$ CI $0.63-16.87$, for HER + relative to luminal-type cases). After adjustment of the Ki-67 index the differences disappeared (TN 1.14, 95\% CI 0.36-3.66, HER2 0.97, 95\% CI 0.32-2.98).

\section{Discussion}

In Finland, the proportion of HER2 + breast cancers in all age groups has been approximately $15 \%$ [17]. Among patients aged 50 to 69 years in our study, the proportion of HER 2 + breast cancers was $12 \%$, and in screening, the proportion of HER $2+$ cancers was only $10 \%$. The lower proportion is partly due to the higher percentage of HER2 + and $\mathrm{TN}$ cancers in patients younger than 50 years. The larger proportion among IBC $(15 \%)$ can be explained by the fact that HER 2 + cancers are rapidly growing, with a shorter asymptomatic and preclinical detectable phase, and therefore often surface clinically between screening rounds. The lower frequency of screen-detected invasive HER $2+$ cancers might be explained by the increased presentation of screendetected in situ cancers, which are often HER $2+$. Digital mammography detects more in situ cancers than film mammography [18], and currently, when older women are invited to the screening, part of their cancers are detected as in situ cancer too. In our study, the proportion of $\mathrm{TN}$ breast cancers in patients aged 50-69 years was 6\%, and the proportion of SDBCs was 5\%. Previous studies have shown similar results, with $4-7 \%$ of $\mathrm{TN}$ cases in screen-detected breast cancers among women aged from 50 to $65 / 70$ years $[2,11,12,15]$. In our study in 50-69-year-old women the proportion of TN cancers among NSBCs was $11 \%$ while of PSBCs it was $5 \%$. This can be due to the fact that part of the hormone-positive cancers are so slow-growing that they don't become symptomatic until after screening age, but also some hormonepositive tumors at an early stage might change to hormonenegative cancers if left to a late-stage but it is not known how much this is happening.

Even though HER $2+$ and TN breast cancers are considered rapidly growing, the majority $(59 \%$ and $57 \%$, 
Table 3 Histopathological features of TN breast cancers in the detection groups

\begin{tabular}{|c|c|c|c|c|}
\hline & $\begin{array}{l}\text { Screen-detected can- } \\
\text { cers (SDBC) }\end{array}$ & Interval cancers (IBC) & $\begin{array}{l}\text { No participation in screening } \\
\text { cancers (NSBC) }\end{array}$ & $p$-value \\
\hline Number of tumors & 27 & 11 & 9 & \\
\hline \multicolumn{5}{|l|}{ Tumor size } \\
\hline Smaller than $2 \mathrm{~cm}$ & $22(81 \%)$ & $8(73 \%)$ & $1(11 \%)$ & $\begin{array}{l}0.4026 \text { (SDBC versus IBC), } \\
0.0002 \text { (SDBC versus NSBC), } \\
0.0002 \text { (PSBC versus NSBC) }\end{array}$ \\
\hline $2 \mathrm{~cm}$ or larger & $4(15 \%)$ & $3(27 \%)$ & $8(89 \%)$ & \\
\hline Size unknown & $1(4 \%)$ & 0 & 0 & \\
\hline \multicolumn{5}{|l|}{ Nodal status } \\
\hline pNo & $19(70 \%)$ & $6(55 \%)$ & $3(33 \%)$ & $0.4573,0.1111,0.1292$ \\
\hline $\mathrm{pN}+$ & $8(30 \%)$ & $5(45 \%)$ & $6(67 \%)$ & \\
\hline \multicolumn{5}{|l|}{ Distant metastasis } \\
\hline M0 & $26(96 \%)$ & $10(91 \%)$ & $7(78 \%)$ & $0.5,0.1479,0.1605$ \\
\hline$M+$ & $1(4 \%)$ & $1(9 \%)$ & $2(22 \%)$ & \\
\hline \multicolumn{5}{|l|}{ Histological Grade } \\
\hline Grade 1 & $1(4 \%)$ & 0 & 0 & \\
\hline Grade 2 & $5(19 \%)$ & 0 & 0 & \\
\hline Grade 3 & $19(70 \%)$ & $11(100 \%)$ & $7(78 \%)$ & $0.1479,0.2964,0.5671^{*}$ \\
\hline Grade unknown & $2(7 \%)$ & 0 & $2(22 \%)$ & \\
\hline Ki-67<15\% & $5(19 \%)$ & 0 & $1(11 \%)$ & $0.2949,1.000,1.000$ \\
\hline $\mathrm{Ki}-67 \geq 15 \%$ & $22(81 \%)$ & $11(100 \%)$ & $8(89 \%)$ & \\
\hline
\end{tabular}

Fisher's exact test was used for $p$-value calculation

$p$-values compare SDBC versus IBC and SDBC versus NSBC and PSBC (SDBC + IBC) versus NSBC groups

$p N O$, no postoperative axillary metastases; $M O$, no distant metastases; $p N+$ axillar and $M+$ distant metastases; $K i-67$ tumor proliferation rate; $T N$, triple-negative, negative for $E R$ estrogen receptor; $P R$, progesterone receptor; and $H E R 2$, HER2 oncogene amplification

*p-value compares Grade 3/(Grade $1+$ Grade 2)

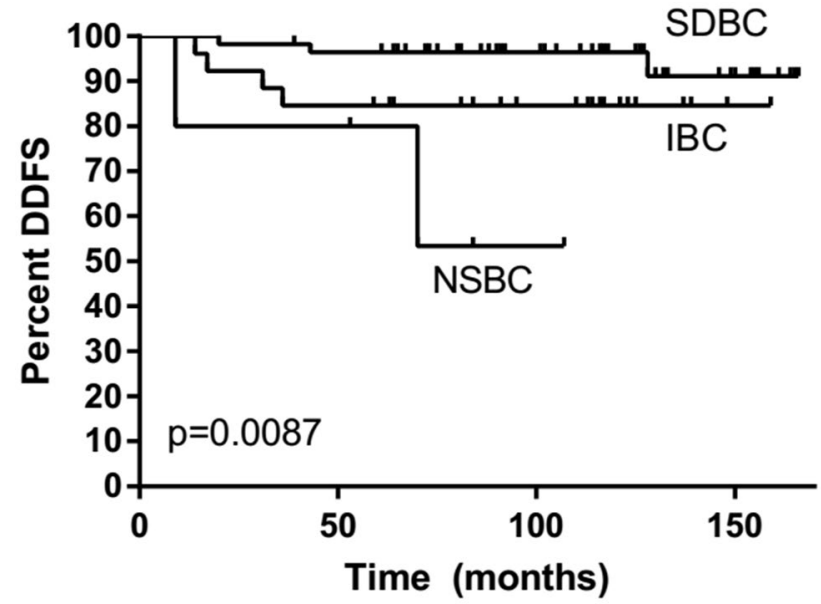

Fig. 1 Distant disease-free survival (DDFS) of HER2-positive (estrogen and progesterone receptor-negative or positive and HER2 oncogene positive) breast cancers among screen-detected (SDBC), interval (IBC), and nonparticipant (NSBC) cases

respectively) of them were detected by population-based screening in this age group. This is in line with a previous study [19]. In our study, SDBCs were $77 \%$ of the PSBCs.

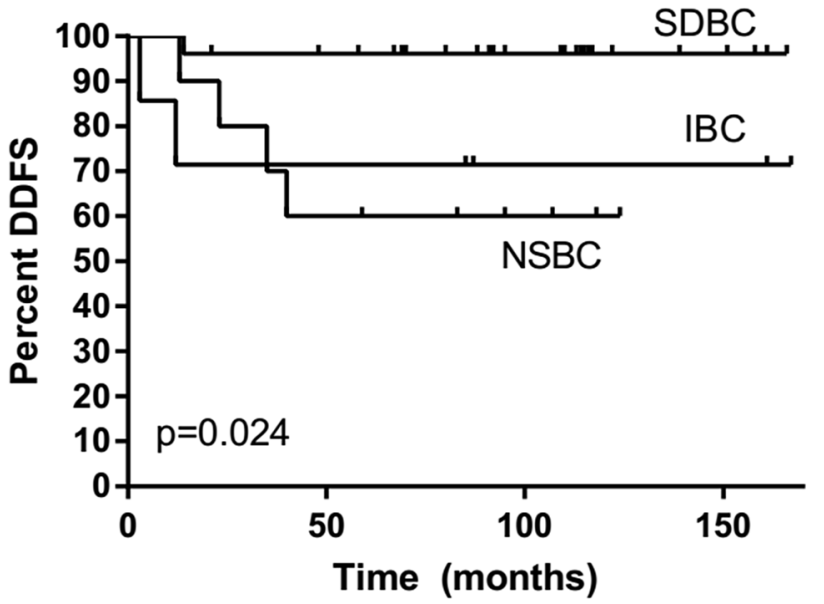

Fig. 2 Distant disease-free survival (DDFS) of triple-negative (estrogen and progesterone receptor-negative and HER2 oncogene negative) breast cancers among screen-detected (SDBC), interval (IBC), and nonparticipant (NSBC) cases

The proportions were almost the same in HER $2+(69 \%)$ and TN (71\%) groups which suggest only a minor length bias phenomenon. This shows that HER $2+$ and TN cancers 


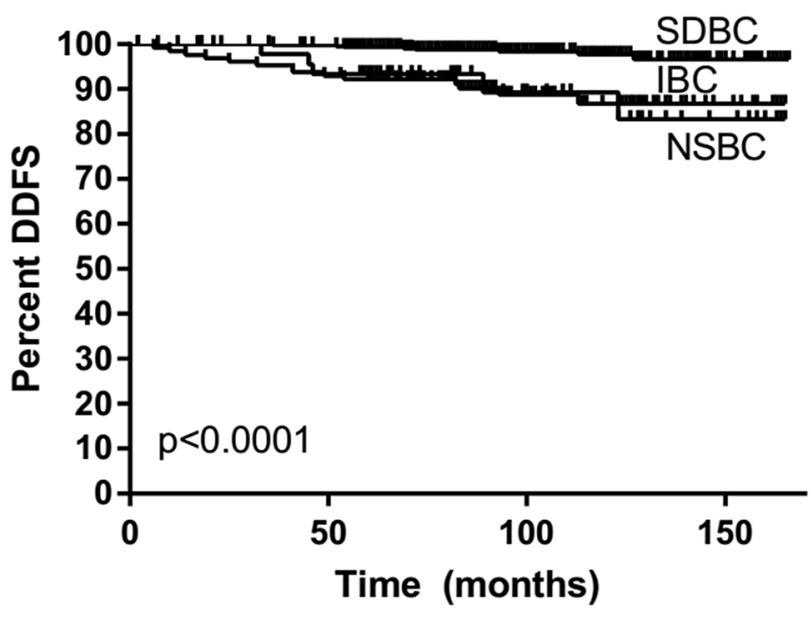

Fig. 3 Distant disease-free survival (DDFS) of luminal type (estrogen and/or progesterone receptor-positive and HER2 oncogene negative) breast cancers among screen-detected (SDBC), interval (IBC), and nonparticipant (NSBC) cases

can be detected by screening almost as well as cancers in general.

Tumor size, nodal status, and distant metastases are the main determinants of patient prognosis. Screen-detected cancers are typically small and node-negative. In our study, screen-detected cancers were smaller than $2 \mathrm{~cm}$ and nodenegative in HER $2+(79 \%, 84 \%)$ and TN $(81 \%, 70 \%)$ cases detected by screening. However, in early pT1abN0 tumors, HER 2 + cases may have a substantial risk for recurrence unless treated with adjuvant therapy [20,21]. For this reason, adjuvant therapy is also recommended for patients with small node-negative HER2 + breast cancer [20, 22]. TN cancers have a substantial risk of relapse, irrespective of additional variables such as grade, lymph node status, and tumor size [23].

HER 2 + and TN cancers are considered to be aggressive and in our study, despite the detection method HER $2+$ and TN breast cancers were often histological grade 3 and even more often displayed a high proliferation rate (Ki-67). It is also known that they have a poorer prognosis than other molecular types of breast cancers. Results from the Swedish Two-County Trial have shown that mortality from histological grade 3 breast cancers can be decreased by invitation to screening [24]. And the 20-year follow-up showed that participation in screening degreased fatal breast cancer incidence significantly compared to those who did not participate[25]. We chose to invest women who were all invited to screening and among them, the best distant disease-free survival of HER $2+$ and TN cancers was in screen-detected cancers. Also, the prognosis of these cancers detected in women who participated in screening was far better than those who did not. Differences in disease-free survival between screendetected luminal and aggressive cancers (HER2 + and TN) disappeared after adjustment for the Ki-67 tumor proliferation marker, which suggests that tumor aggressiveness is mediated by more rapid cell turnover reflected by Ki- 67 .

Among HER2 + cancers, the survival difference seems to be explained by an earlier stage of cancer, but in TN cancers, many interval cancers were small, while almost one-third of screen-detected TN cancers were already node-positive. In TN cancers, tumor size was only weakly correlated with lymph node metastasis [23], but our findings showed that screening can detect TN cancers early enough to influence prognosis. Some studies have reported better survival in screen-detected than clinically detected HER 2 + and TN cancers [2, 26-28], but we found no published reports of more favorable survival in screendetected than interval HER $2+$ and TN cancers.

A strength of our study is the population-based approach, which contains almost complete information for every single case and contains comprehensively and systematically defined molecular subtypes. Undefined cases are due to lack of data because of the minimal proportion of invasion in some cases of ductal in situ cancer.

The limitations of our study are that the evaluation is based on the results of a single screening unit and thus may not be readily generalizable to other settings. Additionally, the number of cases is limited.

\section{Conclusion}

Although screening mainly detects slowly growing, hormone receptor-positive and HER2-negative cancers, our findings also indicate that a substantial proportion of HER $2+$ and TN breast cancers can be detected by screening. The screen-detected HER $2+$ and TN cancers were diagnosed at an earlier stage, and their prognosis was far better than those detected by the symptoms and the prognosis was worse in women who did not participate in screening compared to women who did.

Funding This study was supported by the Eka Grant of the Finnish Medical Foundation.

\section{Compliance with ethical standards}

Conflict of interest The authors have no conflict of interest.

Ethical approval The information of this study was collected retrospectively from registries and this article does not contain any studies with human participants or animals performed by any of the authors. This study was approved by the Ethics Committee of Tampere University. 
Open Access This article is licensed under a Creative Commons Attribution 4.0 International License, which permits use, sharing, adaptation, distribution and reproduction in any medium or format, as long as you give appropriate credit to the original author(s) and the source, provide a link to the Creative Commons licence, and indicate if changes were made. The images or other third party material in this article are included in the article's Creative Commons licence, unless indicated otherwise in a credit line to the material. If material is not included in the article's Creative Commons licence and your intended use is not permitted by statutory regulation or exceeds the permitted use, you will need to obtain permission directly from the copyright holder. To view a copy of this licence, visit http://creativecommons.org/licenses/by/4.0/.

\section{References}

1. Sihto H et al (2008) Molecular subtypes of breast cancers detected in mammography screening and outside of screening. Clin Cancer Res 14(13):4103-4110

2. Dawson SJ et al (2009) Molecular characteristics of screendetected vs symptomatic breast cancers and their impact on survival. Br J Cancer 101(8):1338-1344

3. Domingo L et al (2013) Aggressiveness features and outcomes of true interval cancers: comparison between screen-detected and symptom-detected cancers. Eur J Cancer Prev 22(1):21-28

4. Domingo L et al (2014) Tumor phenotype and breast density in distinct categories of interval cancer: results of populationbased mammography screening in Spain. Breast cancer Res BCR 16(1):R3

5. Redondo M et al (2012) Detection methods predict differences in biology and survival in breast cancer patients. BMC Cancer 12:604

6. Cox B, Sneyd MJ (2013) Bias in breast cancer research in the screening era. Breast 22(6): 1041-1045

7. Joensuu $\mathrm{H}$ et al (2009) Fluorouracil, epirubicin, and cyclophosphamide with either docetaxel or vinorelbine, with or without trastuzumab, as adjuvant treatments of breast cancer: final results of the FinHer Trial. J Clin Oncol 27(34):5685-5692

8. Joensuu H et al (2014) Outcome of patients with HER2-positive breast cancer treated with or without adjuvant trastuzumab in the Finland Capecitabine Trial (FinXX). Acta Oncol (Madr) 53(2):186-194

9. Perez EA et al (2014) Trastuzumab plus adjuvant chemotherapy for human epidermal growth factor receptor 2-positive breast cancer: planned joint analysis of overall survival from NSABP B-31 and NCCTG N9831. J Clin Oncol 32(33):3744-3752

10. Sharma P (2018) Update on the Treatment of Early-Stage TripleNegative Breast Cancer. Curr Treat Options Oncol 19(5):22

11. Bellio $G$ et al (2017) Interval Breast Cancer Versus ScreenDetected Cancer: Comparison of Clinicopathologic Characteristics in a Single-Center Analysis. Clin Breast Cancer 17(7):564-571

12. Caldarella A et al (2013) Biological characteristics of interval cancers: a role for biomarkers in the breast cancer screening. J Cancer Res Clin Oncol 139(2):181-185

13. Musolino A et al (2012) Human epidermal growth factor receptor 2 status and interval breast cancer in a population-based cancer registry study. J Clin Oncol 30(19):2362-2368
14. López-García MÁ et al (2020) Low prevalence of HER2-positive breast carcinomas among screening detected breast cancers. Cancers (Basel) 12(6):1-16

15. O'Brien KM, Mooney T, Fitzpatrick P, Sharp L (2018) Screening status, tumour subtype, and breast cancer survival: a national population-based analysis. Breast Cancer Res Treat. https://doi. org/10.1007/s 10549-018-4877-9

16. Perry N (2006) European guidelines for quality assurance in breast cancer screening and diagnosis. Office for Official Publ. of the Europ, Communities, Luxembourg

17. Koninki K, Tanner M, Auvinen A, Isola J (2009) HER-2 positive breast cancer: decreasing proportion but stable incidence in Finnish population from 1982 to 2005. Breast Cancer Res 11(3):R37

18. Bluekens AMJ, Holland R, Karssemeijer N, Broeders MJM, Den Heeten GJ (2012) Comparison of digital screening mammography and screen-film mammography in the early detection of clinically relevant cancers: A multicenter study. Radiology 265(3):707-714

19. Prange A et al (2018) Higher Detection Rates of Biologically Aggressive Breast Cancers in Mammography Screening than in the Biennial Interval. RöFo-Fortschritte auf dem Gebiet der Röntgenstrahlen und der Bildgeb, Verfahren

20. Hurvitz SA, Gelmon KA, Tolaney SM (2017) Optimal Management of Early and Advanced HER2 Breast Cancer. Am Soc Clin Oncol Educ book 37(37):76-92

21. Fehrenbacher L, Capra AM, Quesenberry CP, Fulton R, Shiraz P, Habel LA (2014) Distant invasive breast cancer recurrence risk in human epidermal growth factor receptor 2-positive T1a and T1b node-negative localized breast cancer diagnosed from 2000 to 2006: a cohort from an integrated health care delivery system. J Clin Oncol 32(20):2151-2158

22. Pernas S, Barroso-Sousa R, Tolaney SM (2018) Optimal treatment of early stage HER2-positive breast cancer. Cancer 124(23):4455-4466

23. Kumar P, Aggarwal R (2016) An overview of triple-negative breast cancer. Arch Gynecol Obstet 293(2):247-269

24. Tabar L et al (2018) Effect of Mammography Screening on Mortality by Histological Grade. Cancer Epidemiol Biomarkers Prev. https://doi.org/10.1158/1055-9965.EPI-17-0487

25. Tabár L et al (2019) The incidence of fatal breast cancer measures the increased effectiveness of therapy in women participating in mammography screening. Cancer 125(4):515-523

26. Kobayashi N et al (2017) Differences in subtype distribution between screen-detected and symptomatic invasive breast cancer and their impact on survival. Clin Transl Oncol. https://doi. org/10.1007/s12094-017-1660-z

27. Crispo A et al (2013) Molecular profiles of screen detected vs. symptomatic breast cancer and their impact on survival: results from a clinical series. BMC Cancer 13:15

28. Kim J et al (2012) Comparison between screen-detected and symptomatic breast cancers according to molecular subtypes. Breast Cancer Res Treat 131(2):527-540

Publisher's Note Springer Nature remains neutral with regard to jurisdictional claims in published maps and institutional affiliations. 